\title{
Observational study of prolonged times to tracheal extubation
}

\author{
Franklin Dexter, PhD $\cdot$ Richard H. Epstein, MD
}

Received: 14 August 2015/Revised: 17 August 2015/Accepted: 15 September 2015/Published online: 22 September 2015

(c) Canadian Anesthesiologists' Society 2015

\section{To the Editor,}

Tabing et al. studied changes in costs and workflow at Vanderbilt University Medical Center when desflurane vaporizers were removed from anesthesia machines in the operating rooms (ORs). ${ }^{1}$ They studied cases that took $\geq 15$ min from the end of the case until the OR exit. In contrast, observational and randomized studies of prolonged times to tracheal extubation have used $\geq 15 \mathrm{~min}$ from the time of finishing applying the surgical dressing on the patient (or its functional equivalent) to tracheal extubation..$^{2-4}$ There is excellent reliability for the dressing on until extubation period (Krippendorff's alpha $=0.989) .{ }^{3}$ Furthermore, prolonged $(\geq 15 \mathrm{~min}$ ) times for that period are associated with longer times to OR exit. ${ }^{2-6}$ From Table 4 of reference ${ }^{6}$, among cases with prolonged times to tracheal extubation, the mean time from end of surgery to OR exit was $28 \mathrm{~min}$. Therefore, among the authors' cases with tracheal intubation and extubation in the OR, what percentage of cases in the before and after periods had times $\geq 28 \mathrm{~min}$ from the end of surgery to OR exit (i.e., as previously studied) or, alternatively, $\geq 30 \mathrm{~min}$ (i.e., what an organization might monitor), and what was the corresponding relative risk and confidence interval?

This letter is accompanied by a reply. Please see Can J Anesth 2016; 63: this issue.

F. Dexter, PhD ( $\square)$

Division of Management Consulting, Department of Anesthesia,

University of Iowa, Iowa City, IA, USA

e-mail: franklin-dexter@uiowa.edu

R. H. Epstein, MD

Sidney Kimmel Medical College at Thomas Jefferson

University, Philadelphia, PA, USA
For sevoflurane, using an approximate Canadian acquisition price $(\$ 200 / 250 \mathrm{~mL})$, fresh gas flow $\left(2 \mathrm{~L} \cdot \mathrm{min}^{-1}\right)$, average vaporizer concentration $(2 \%)$, and OR temperature $\left(20^{\circ} \mathrm{C}\right)$ and pressure $(760 \mathrm{mmHg})$, administration costs are approximately $\$ 11.05$ per hour during anesthesia maintenance. Even though, in the US, sevoflurane acquisition costs are about half of that in Canada, the authors report in their Table 5 that the cost of sevoflurane was $\$ 0.63$ per case. This apparent discrepancy would require explanation and redo of the cost analysis, as necessary. In comparison, the authors' values in Table 5 for isoflurane and desflurane seem reasonable based on typical fresh gas flows (i.e., without feedback to providers). ${ }^{7,8}$

Acknowledgement Ms. Jennifer Espy, BFA, assisted in the preparation of this Letter to the Editor.

Conflicts of interest None declared.

Disclosure The Division of Management Consulting of the Department of Anesthesia, University of Iowa has previously received funding from Abbott Laboratories, Baxter Healthcare, and Merck. Dr. Dexter receives no funds personally other than his salary and allowable expense reimbursements from the University of Iowa and has tenure with no incentive program. He and his family have no financial holdings in any company related to his work other than indirectly through mutual funds for retirement. Income from the Division's consulting work is used to fund Division research.

Funding Departmental.

\section{References}

1. Tabing AK, Ehrenfeld JM, Wanderer JP. Limiting the accessibility of cost-prohibitive drugs reduces overall anesthetic drug costs: a retrospective before and after analysis. Can J Anesth 2015; DOI:10.1007/s12630-015-0442-8. 
2. Dexter F, Bayman EO, Epstein RH. Statistical modeling of average and variability of time to extubation for meta-analysis comparing desflurane to sevoflurane. Anesth Analg 2010; 110: 570-80.

3. Masursky D, Dexter F, Kwakye MO, Smallman B. Measure to quantify the influence of time from end of surgery to tracheal extubation on operating room workflow. Anesth Analg 2012; 115: 402-6.

4. Agoliati A, Dexter F, Lok J, et al. Meta-analysis of average and variability of time to extubation comparing isoflurane with desflurane or isoflurane with sevoflurane. Anesth Analg 2010; 110: 1433-9.

5. Epstein RH, Dexter F, Brull SJ. Cohort study of cases with prolonged tracheal extubation times to examine the relationship with duration of workday. Can J Anesth 2013; 60: 1070-6.
6. Dexter F, Epstein RH. Increased mean time from end of surgery to operating room exit in a historical cohort of cases with prolonged time to extubation. Anesth Analg 2013; 117: 1453-9.

7. Nair BG, Peterson GN, Neradilek MB, Newman SF, Huang EY, Schwid HA. Reducing wastage of inhalation anesthetics using realtime decision support to notify of excessive fresh gas flow. Anesthesiology 2013; 118: 874-84.

8. Epstein $R$, Dexter $F$, Patel $N$. Influencing anesthesia provider behavior using anesthesia information management system data for near real-time alerts and post hoc reports. Anesth Analg 2015; DOI:10.1213/ANE.0000000000000677. 